Dicky Warnedi, Hasbullah Malau I Pengelolaan dan Pemanfaatan Keuangan dan Aset Nagari di Nagari Taratak Baru Kecamatan Tanjung Gadang Kabupaten Sijunjung

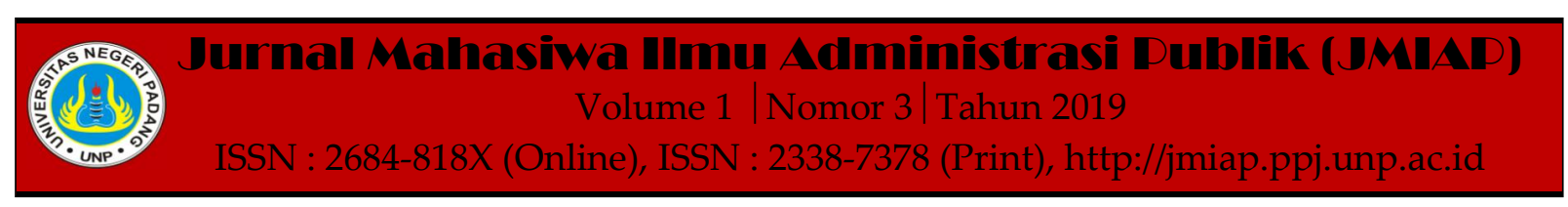

\title{
PENGELOLAAN DAN PEMANFAATAN KEUANGAN DAN ASET NAGARI DI NAGARI TARATAK BARU KECAMATAN TANJUNG GADANG KABUPATEN SIJUNJUNG
}

\author{
Dicky Warnedi ${ }^{1(a)}$, Hasbullah Malau ${ }^{2(b)}$ \\ ${ }^{1}$ Jurusan Ilmu Administrasi Negara, Universitas Negeri Padang \\ ${ }^{2}$ Jurusan Ilmu Administrasi Negara, Universitas Negeri Padang \\ a)dickywarnedi@gmail.com, ${ }^{b)}$ hasbullahmalau@gmail.com
}

\begin{abstract}
This research wants to know and describe and analyze the processes of financial management and utilization, village assets and the readiness of the village government in financial management and utilization as well as village assets as well as problems in financial management and assets of Nagari in Sijunjung Regency. This research uses descriptive qualitative approach method. This research was conducted in Nagari Taratak Baru in Sijunjung Regency. The researcher chooses informants using purposive sampling technique. The data of this study are primary and secondary data. Data collected by interview, observation and documentation study. Data validity testing techniques with triangulation methods. While the data analysis technique refers to the technique developed by Sugiyono. The results of this study indicate that village asset and financial management in Sijunjung Regency is still not good. There are still many obstacles in the management of finance and assets, the constraints on the planned budget of the income and expenditure of the village that have not been on time and there are still many obstacles in the human resources expert in accounting. In the management of nagari assets, there are still problems with the inventory of nagari assets whose data processing is still poor and land owned by the nagari government that is not yet in association.
\end{abstract}

Keywords : Management, Nagari Finance, Nagari Assets

Corresponding author. Email.dickywarnedi@gmail.com, hasbullahmalau@gmail.com

How to cite this article. Warnedi. D \& Malau. H. (2019). Pengelolaan dan Pemanfaatan Keuangan dan Aset Nagari di Nagari Taratak Baru Kecamatan Tanjung Gadang Kabupaten Sijunjung. Jurnal Mahasiwa Ilmu Administrasi Publik (JMIAP) Jurusan Ilmu Administrasi Negara Fakultas Ilmu Sosial Universitas Negeri Padang, Volume 1 (3), Hal. 85-90.

http://jmiap.ppj.unp.ac.id

ISSN : 2684-818X (Online), ISSN : 2338-7378 (Print)

Copyright $(2019$. Published by Pusat Kajian-Pemberdayaan dan Pelayanan Masyarakat (PK-P2M) FIS UNP Padang 
Dicky Warnedi, Hasbullah Malau I Pengelolaan dan Pemanfaatan Keuangan dan Aset Nagari di Nagari Taratak Baru Kecamatan Tanjung Gadang Kabupaten Sijunjung

\section{PENDAHULUAN}

UU Nomor 6 Tahun 2014 tentang Desa, desa berwenang mengurus tata pemerintahan sendiri serta seluruh kegiatan dalam bentuk pembangunan untuk meningkatkan kesejahteraan kehidupan masyarakat desa. Desa (disebut Nagari di Provinsi Sumatera Barat), nagari diharapkan kreatif dalam mengelola pemerintahan dan semua sumber daya alam maupun sumber daya manusia yang dimiliki.

Desa (disebut Nagari di Provinsi Sumatera Barat) adalah bagian penting dari Indonesia. Membangun nagari sama hal nya membangun seluruh bagian dari masyarakat Indonesia. Karena lebih dari $80 \%$ masyarakat Indonesia berada di desa-desa seluruh Indonesia. Desa berperan dalam pemerintahan dan mempunyai penuh tanggung jawab besar. Sebab itu pemerintah Nagari seharusnya menerapkan semua prinsip yang akuntabilitas untuk pemerintahannya, dan akhir dari kegiatan menyelenggaraan pemerintahan Nagari seharusnya bisa dipertanggungjawabkan pada masyarakat Nagari sesuai dari ketentuan yang ada. Kesiapan adalah hal yang harus dilaksanakan oleh individu dan organisasi untuk melaksanakan sesuatu. kesiapan dari pemerintah Nagari untuk menjalankan tugasnya yang sesuai dengan Undang-Undang Nomor 6 Tahun 2014 tentang Desa atau Nagari. Kesiapan pemerintah adalah masalah penting dalam implementasi kebijakan Undang-undang Nomor 6 Tahun 2014 tentang Desa.

Berkaitan dengan pemerintahan Nagari, untuk mengelola keuangan Nagari di Kabupaten Sijunjung, pemerintah kabupaten sijunjung mengeluarkan peraturan daerah (Perda) kabupaten sijunjung Nomor 2 tahun 2014. Nagari Taratak Baru, Kecamatan Tanjung Gadang. Nagari Taratak Baru merupakan Nagari yang baru terbentuk pada tahun 2003.

\section{TINJAUAN PUSTAKA}

\section{Konsep Pengelolaan Keuangan Desa}

Pengertian keuangan desa menurut UU Nomor 6 Tahun 2014 pasal 71 adalah semua hak dan kewajiban desa yang dapat dinilai dengan uang serta segala sesuatu berupa uang dan barang yang berhubungan dengan pelaksanaan hak dan kewajiban Desa. Hak dan kewajiban tersebut menimbulkan pendapatan, belanja, pembiayaan yang perlu diatur dalam pengelolaan keuangan desa yang baik.

Pendapatan desa sesuai pasal 72 Undang-Undang Nomor 6 Tahun 2014 tentang Desa bersumber dari:

a. Pendapatan Asli Desa;

b. Alokasi Anggaran Pendapatan dan Belanja Negara (Dana Desa);

c. Bagian Hasil Pajak Daerah dan Retribusi Daerah Kabupaten/Kota;

d. Alokasi Dana Desa;

e. Bantuan Keuangan dari APBD Provinsi dan APBD Kabupaten/Kota;

f. Hibah dan Sumbangan yang Tidak Mengikat dari Pihak Ketiga;

g. Lain-lain Pendapatan Desa yang Sah.

Arif dalam Budiarti (2016:19) mendefinisikan bahwa pengelolaan keuangan desa adalah keseluruhan kegiatan yang meliputi perencanaan, penganggaran, pelaporan pertanggung jawaban, dan pengawasan keuangan desa. Berdasarkan Peraturan Menteri 113 Tahun 2014 tentang pengelolaan keuangan desa pasal 1 ayat (7) menyampaikan bahwa pengelolaan keuangan desa merupakan keseluruhan kegiatan yang meliputi perencanaan, pelaksanaan, penatausahaan, pelaporan dan pertanggung jawaban keuangan desa.

a) Perencanaan

Menurut Sutarno (2004: 109), perencanaan diartikan sebagai perhitungan dan penentuan tentang apa yang dijalankan dalam rangka mencapai tujuan tertentu dimana 
menyangkut tempat, oleh siapa pelaku itu atau pelaksanaan tata cara mencapai tujuan tersebut. Dari pernyataan tersebut perencanaan dapat diartikan sebagai pemilihan sekumpulan kegiatan dan pemusatan selanjutnya apa yang harus dilakukan, kapan, bagaimana dan oleh siapa.

b) Pelaksanaan dan penatausahaan Menurut Rue dan Byars (2006: 6) Organizing is grouping activities, assigning activities an providing the authority necessary to carry out the activities (pengorganisasian merupakan pengelompokan kegiatan-kegiatan penugasan kegiatan-kegiatan penyediaan keperluan, wewenang untuk melaksanakan kegiatannya. Pelaksanaan atau Organizing dapat diartikan sebagai implementasi dari perencanaan dan pengorganisasian, dimana seluruh komponen yang berada dalam satu sistem dan satu organisasi tersebut bekerja secara bersama-sama sesuai dengan bidang masing-masing untuk dapat mewujudkan tujuan.

c) Pelaporan dan Pertanggungjawaban

Menurut Arnos Kwaty dalam Hansen (2005: 116) mengatakan: "pertanggungjawaban adalah sistem yang mengukur berbagai hasil yang dicapai oleh setiap pusat pertanggungjawaban menurut informasi yang dibutuhkan oleh para pimpinan untuk mengoperasikan pusat-pusat pertanggungjawaban mereka"

Dari konsep di atas maka dapat disimpulkan bahwa pertanggungjawaban adalah sistem yang mengukur perencanaan dengan anggaran dan kegiatan dalam berbagai hasil yang dicapai oleh setiap pusat pertanggungjawaban yang harus dipertanggungjawabkan dalam bentuk laporan pengendalian periodik.

\section{Konsep Pengelolaan Aset Desa}

UU Nomor 6 Tahun 2014 tentang Desa memberikan mandat bagi desa untuk mengatur dan mengelola aset serta kekayaan desa bagi peningkatan kesejahteraan dan taraf penghidupan masyarakat. Hal ini memberikan peluang bagi desa untuk mengembangkan aset desa sebagai sumber penghidupan berkelanjutan yang nantinya berkontribusi bagi pengentasan kemiskinan.

UU Nomor 6 Tahun 2014 tentang Desa mendefinisikan aset desa sebagai barang milik desa yang berasal dari kekayaan asli Desa, dibeli atau diperoleh atas beban Anggaran Pendapatan dan Belanja Desa atau perolehan hak lainnya yang sah.

\section{Kesiapan Pemerintah Desa}

Kesiapan merupakan hal utama yang harus dilakukan baik oleh individu maupun oleh organisasi dalam melakukan sesuatu. Kesiapan juga diartikan sebagai alat kontrol agar tujuan organisasi dapat terwujud. Kesiapan pemerintah desa merupakan masalah utama dalam implementasi kebijakan Undang-undang Nomor 6 Tahun 2014 tentang Desa. Hal ini dikarenakan tanpa adanya kesiapan pemerintah desa maka target Undang Undang Nomor 6 Tahun 2014 tentang Desa tidak akan tercapai sesuai dengan yang di cita-citakan oleh Negara. (Budiarti, 2016:5).

Dalam konteks nyata, kesiapan yang dimaksud dalam penelitian ini adalah kesiapan pemerintah desa dalam hal pengelolaan keuangan dan aset desa. Adapun hal-hal yang menjadi fokus penelitian ini adalah kesiapan dalam penataan organisasi, kesiapan sistem, kesiapan sumber daya manusia dan kesiapan sarana dan prasarana dalam pengelolaan keuangan dan aset desa.

\section{METODE PENELITIAN}

Penelitian ini adalah penelitian kualitatif. Penelitian ini dilakukan di Nagari Taratak Baru, Kec. Tanjung Gadang, Kab. Sijunjung. Data diambil dengan metode 
Dicky Warnedi, Hasbullah Malau I Pengelolaan dan Pemanfaatan Keuangan dan Aset Nagari di Nagari Taratak Baru Kecamatan Tanjung Gadang Kabupaten Sijunjung

purposive sampling yaitu menentukan informan dengan pertimbangan tertentu yang dipandang dapat memberikan data secara maksimal. Informan dari penelitian ini merupakan pihak-pihak yang memiliki informasi lengkap sesuai kebutuhan peneliti.

Data Primer dalam penelitian ini diperoleh melalui observasi dan wawancara yang berkaitan dengan pengelolaan dan pemamfaatan keuangan dan aset nagari. Data sekunder yaitu diperoleh melalui dokumen-dokumen seperti keadaan geografis Nagari Taratak Baru, Pendidikan dan Pemerintahan Nagari. Keabsahan data dilakukan dengan menggunakan teknik triangulasi sumber. Triangulasi metode digunakan untuk mencocokkan sumber yang penulis peroleh dari wawancara, observasi dan studi kepustakaan.

\section{HASIL DAN PEMBAHASAN}

\section{Pengelolaan Keuangan Nagari}

Dalam pengelolaan keuangan nagari, peneliti memaparkan sumber-sumber keuangan Nagari Taratak Baru.

a) Perencanaan

Perencanaan di nagari disusun melalui forum Musyawarah tahunan para pemangku kepentingan Nagari untuk menyepakati dalam Perencanaan Pembangunan Nagari . biasanya setiap tahun pada bulan januari menyelenggarakan musenbang.

b) Pelaksanaan

Tahap pelaksanaan adalah suatu kegiatan untuk melakukan rencana yang telah ditetapkan. Pengeluaran dan pemasukan Nagari melalui rekening kas nagari, semuanya harus didukung oleh bukti dalam progam pelaksanaan.

c) Pelaporan

Laporan ini belum terselenggara dengan optimal karena pemerintah Nagari Taratak Baru masih dalam tahap pembelajaran, dan harus banyak lagi mengikuti pelatihan. Hal ini bisa mengakibatkan keterlambatan dalam pencairan dana.

\section{Kesiapan Pemerintah Nagari Dalam Pengelolaan dan Pemanfaatan Keuangan dan Aset Nagari}

Perangkat nagari sangat berperan dalam menentukan keberhasilan pembangunan nagari, karena pentingnya peran pemerintah sehingga dibutuhkan kesiapan untuk menguasai pemerintahan berdasarkan peraturan yang berlaku sesuai perundang undangan. Kesiapan pemerintah dalam pengelolaan aset nagari dan keuangan terbagi dua yaitu :

a) Persiapan Organisasi

Pemerintah nagari dalam mengelola keuangan nagari membutuhkan organisasi yang berpengalaman dalam mengurus keuangan dan aset nigari.

b) Persiapan Sistem

Pengelolaan keuangan nagari dimulai dari perencanaan, penganggaran, pelaksanaan, pelaporan hingga pertanggungjawaban dilakukan dengan aplikasi Sistem Keuangan Nagari/ desa (Siskeudes). Aplikasi ini dipasang hanya dalam laptop Bendahara Nagari saja. Sehingga yang bisa mengoperasikannya Bendahara Nagari saja.

Aplikasi Sistem Keuangan Nagari adalah aplikasi yang dibuat oleh Badan Pengawasan Keuangan dan Pembangunan (BPKP) untuk meningkatkan kualitas pengelolaan keuangan nagari. Fitur-fitur yang ada dalam aplikasi tesebut diciptakan dengan sederhana sehingga pengguna mudah dalam menggunakannya.

Uraian di atas telah menjelaskan bahwa sebelumnya dalam pengelolaan dan pemamfaatan keuangan dan aset nagari belum maksimal. Masih banyak kendala dalam pengelolaan keuangan dan aset, kendalanya pada perencanaan pendapatan dan belanja nagari yang belum tepat waktu dan masih kurangnya SDM yang ahli. Pada pengelolaan aset nagari masih terdapat permasalahan pada inventaris aset nagari yang pengolahan datanya masih kurang baik dan tanah milik pemerintah nagari 
Dicky Warnedi, Hasbullah Malau I Pengelolaan dan Pemanfaatan Keuangan dan Aset Nagari di Nagari Taratak Baru Kecamatan Tanjung Gadang Kabupaten Sijunjung

yang belum bersetiikat. Dari hasil ini diketahui bahwa peran pemerintah dalam mengelola dan memamfaatkan keuangan dan aset nagari belum dirasakan oleh masyarakat.

\section{PENUTUP}

Berdasarkan hasil penelitian dan pembahasan yang peneliti lakukan, maka dapat ditarik kesimpulan sebagai berikut :

1) Sudah terpenuhinya kesiapan organisasi dan diatur oleh peraturan Permendagri No 113 Tahun 2014 tentang Pengelolaan Keuangan desa.

2) Sudah terlaksananya kesiapan sistem keuangan nagari dibantu dengan aplikasi Sistem Keuangan Nagari.

3) Kesiapan SDM masih belum optimal. Pelatihan yang sudah dilakukan belum diterapkan sepenuhnya oleh pemerintah nagari.

4) Sudah mulai memadainya kesiapan sarana dan prasarana dalam mengelola keuangan nagari karena pengelolaan keuangan menjadi prioritas dalam pengelolaan keuangan di nagari tersebut.

5) Belum adanya kesiapan pemerintah nagari dalam pengelolaan aset nagari dan pengelolaan keuangan. Hal ini disebabkan beberapa hal:

- Pengelolaan dilakukan seadanya karena aset nagari Taratak Baru sangat minim.

- Tidak adanya sosialisasi kepada pemerintah terkait Peraturan perundangundangan dalam pengelolaan aset nagari.

\section{DAFTAR KEPUSTAKAAN}

Herlina, Hetti. 2013. -Analisis Faktorfaktor yang Mempengaruhi Kesiapan Pemerintahan Daerah Dalam Implementasi PP 71 Tahun 2010" Skripsi.
Dipublikasikan. Universitas Negeri Padang. (unp.ac.id/file?...\%20Analisis\%20fakt or-faktor\%20...). \{5 Mei 2016\}.

Wiyono, Adrianto Sugiarto. 2008. -Hubungan Kepemimpinan dengan Kesiapan Implementasi Knowledge Management dalam Organisasi”.

Jurnal(http://rianadrianto.files.wordpress.c om/2008/06/kepemimpinandankesiapa n-km.pdf). \{5 Juni 2016\}.

Budiarti, Melda. 2016. -Kesiapan dan Strategi Pemerintah Desa dalam Implementasi Kebijakan UndangUndang Nomor 6 Tahun 2014 tentang Desa (Studi Penelitian di Desa Sumur Tujuh, Kec. Wonosobo, Kab. Tanggamus)\|. Skripsi. Universitas Lampung.

(http://digilib.unila.ac.id/.../...)

Desember 2016\}.

Primasari, Andin Niantima. 2011. -Pengaruh Restrukturisasi Organisasi Terhadap Efektifitas Pelaksanaan Tugas Pokok dan Fungsi Dinas Pertanian, Tanaman Pangan dan Holtikultura, Peternakan dan Perkebunan Kabupaten Pesisir Selatanl. Tesis. Dipublikasikan. Universitas Andalas. (http://Repository.unand.ac.id/16801/1 /tesis.pdf) \{3 Januari 2017\}.

Hadiyanti, Rini. 2013. - Implementasi Peraturan Pemerintah Nomor 8 Tahun 2003 tentang Pedoman Organisasi Perangkat Daerah Pemerintah Kota Samarinda.

(http://Ejournal.ip.fisip.ummul.ac.id). \{3 Januari 2017\}.

Undang-Undang Otonomi Daerah Nomor 32 Tahun 2004 Tentang Pemerintah Daerah.

Undang-Undang Nomor 6 Tahun 2014 Tentang Desa. 
Dicky Warnedi, Hasbullah Malau I Pengelolaan dan Pemanfaatan Keuangan dan Aset Nagari di Nagari Taratak Baru Kecamatan Tanjung Gadang Kabupaten Sijunjung

Peraturan Menteri Dalam Negeri Republik Indonesia Nomor 52 Tahun 2015 tentang Pedoman Penyusunan Anggaran Pendapatan dan Belanja Daerah Tahun Anggaran 2016.
Peraturan Menteri Dalam Negeri Republik Indonesia Nomor 113 Tahun 2014 tentang Pengelolaan Keuangan Desa.

Peraturan Menteri Dalam Negeri Republik Indonesia Nomor 1 Tahun 2016 tentang Pengelolaan Aset Desa. 